\title{
NEUROGENIC MODULATION OF URETHRAL RESISTANCE IN THE GUINEA PIG
}

\author{
J. GROEN*, E. VAN ASSELT, R. VAN MASTRIGT, M. KRANSE AND R. BOSCH
}

\section{ABSTRACT}

Purpose: The resistance offered to urinary flow by the urethra is one of the factors determining the course of micturition. It was the aim of the present work to study the dependence of urethral resistance on the degree of relaxation of the urethra.

Materials and Methods: Experiments were done in the guinea pig. Ten animals were used. In 5 animals saline was forced through the (unrelaxed) urethra at imposed flow rates in the range of 1.1 to $43.0 \mathrm{ml}$. per minute while the urethral pressure was measured. Second degree polynomials were fitted to the pressure/flow data. In the other 5 animals micturition contractions were evoked and pressure/flow plots were derived from the measured signals. A straight line was fitted to the lowest pressure values at each flow rate in these plots. These pressure values represent the most relaxed state of the urethra in these voidings.

Results: The pressures measured in the unrelaxed urethra were much higher than the pressures measured during voiding in the same flow rate range, but the intercepts of the mathematical equations fitted to the pressure/flow data on the pressure axis were not significantly different in the 2 groups.

Conclusions: The unrelaxed urethra has a much "steeper" pressure/flow characteristic than the relaxed urethra. However, the urethral closing pressure, that is, the intercept of the pressure/ flow characteristic on the pressure axis, does not depend on the state of relaxation of the urethra.

KEY WORDS: guinea pigs, bladder, urodynamics, urination, urethral obstruction

The course of micturition depends on the contraction strength of the bladder and the resistance offered to urinary flow by the urethra. These 2 properties are modulated by the nervous system. A complete understanding of the function of the lower urinary tract therefore requires knowledge of the modulation mechanism. In previous work the dependence of bladder contractility on stimulation intensity was studied in a guinea pig bladder model in vitro. 1,2 The aim of the present work was to study the modulation of urethral resistance to flow by neurogenic stimulation in the guinea pig in vivo.

The resistance offered to flow by the urethra is reflected by the pressure head needed to drive a given flow rate through the urethra. The relationship between the instantaneous flow rate and the associated pressure was called "urethral resistance relation" by Griffiths. ${ }^{3}$ In the normal urethra the urethral resistance relation depends on the state of relaxation of the urethral musculature, especially the urethral sphincter. This means that the urethral resistance relation varies with the intensity of neurogenic stimulation. In this study urethral resistance was measured at 2 levels of neurogenic stimulation: during a micturition contraction, when the urethra was relaxed, and in the absence of such a contraction, when it was contracted. Micturition contractions were volume evoked. Pressure/flow plots were derived from the measured pressure and flow rate signals. The lowest pressure values at each flow rate in these plots, which occur during the most relaxed state of the urethra, were compared with the pressures measured when flow was forced through the unrelaxed urethra.

\section{MATERIALS AND METHODS}

Ten male guinea pigs weighing 817 to $1280 \mathrm{~g}$. were used. Each animal was anesthetized with urethane $(1.2 \mathrm{~g} . \mathrm{kg}$. in-

Accepted for publication October 10, 1995.

* Requests for reprints: Department of Urology, Room EE 1630 , Erasmus University Rotterdam, P.O. Box 1738, 3000 DR Rotterdam, The Netherlands. traperitoneally) and rested on a heating pad to maintain body temperature. In 5 of the animals the urethral resistance relation was determined in the unrelaxed urethra, as follows: The bladder and proximal urethra as well as the most superficial distal part of the urethra were exposed through an abdominal incision. A $24 \mathrm{~g}$ angiocatheter was inserted into the proximal urethra, just distal to the bladder neck. Proximally, the urethra was sealed with a clamp to prevent leakage to the bladder. The catheter was connected to a Harvard infusion pump and a disposable pressure transducer with polyethylene tubes (i. d. $1.5 \mathrm{~mm}$.) and a $\mathrm{Y}$ connector. The distance between the catheter tip and the pressure transducer was $50 \mathrm{~cm}$. The distal part of the urethra was dissected from the underlying tissue. A 3-mm. diameter ultrasonic flow probe was placed around this part and connected to a T106 flowmeter (Transonic Systems Inc., Ithaca, New York). The flow probe of this flow rate measurement system contains 2 ultrasound transducers located at one side of the urethra, while a reflector is located at the other side. The 2 transducers pass ultrasonic signals back and forth, alternately intersecting the urine flow in upstream and downstream directions. The flowmeter measures the time it takes for the waves to travel from one transducer to the other. The difference between the upstream and downstream integrated transit times is a measure of the flow rate. Room temperature saline was pumped through the urethra. Flow rates of 1.1, $2.2,5.4,10.8,21.4$ and $43.0 \mathrm{ml}$. per minute were applied in a semirandom order while pressure was measured. The pressure and flow rate signals were sampled with a personal computer at a rate of $100 \mathrm{~Hz}$. Figure 1 illustrates that, following a transient, steady state readings were attained for both the pressure and flow rate signal. The measured pressure signal was averaged over a time interval of 2.0 to 20 seconds (depending on the flow rate) during this steady state. The measured pressure values were corrected by subtracting the pressure loss in the measuring system caused by the imposed flow rate. This pressure loss, which is due to the 
A

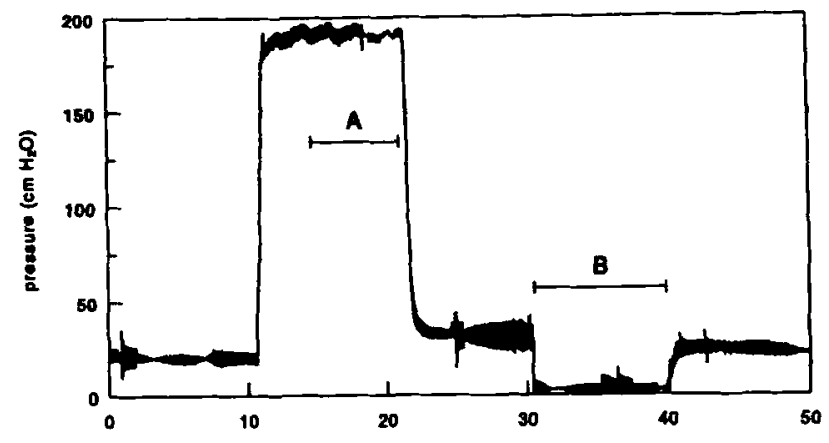

B

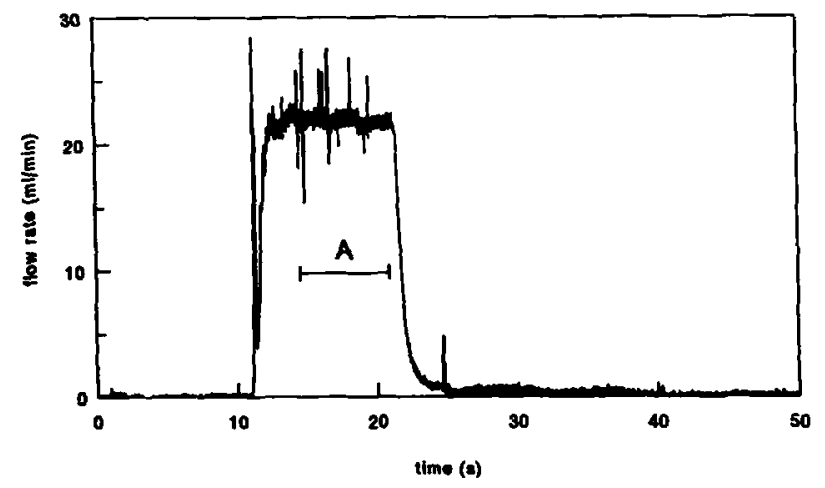

Fig. 1. Typical example of pressure $(A)$ and flow rate $(B)$ measured in unrelaxed urethra. At $t=10.7$ seconds, infusion pump was switched on. Steady reading was attained in time interval indicated with $A$. Signals were averaged over this interval. Pressure measured in time interval $B$ is atmospheric pressure, measured by opening tubing system to air. In absence of flow, measured pressure does not reflect pressure in urethra. These parts of pressure tracing should be ignored.

resistance to flow in the catheter and to the Bernoulli effect, was determined in separate measurements (see Results). Atmospheric pressure was used as the reference level. Using the software package SPSS version 5.0.2 (SPSS, Inc., Chicago, Illinois), second degree polynomials defined by the equation

$$
P_{u r a}=p_{u r a . c l o s . e s t}+a_{1} Q+a_{2} Q^{2}
$$

were fitted to the measured pressure/flow data. In this equation, $p_{\text {ura }}$ is the (corrected) measured urethral pressure and $Q$ is the imposed flow rate. The parameter $p_{\text {ura.clos.ent }}$ is the intercept of the urethral resistance relation on the pressure axis and was considered an estimate for the urethral closing pressure; the parameters $a_{1}$ and $a_{2}$ describe the slope and curvature of this relation. Two subsets of the polynomials were applied: one without a linear term $\left[a_{1}=0\right.$ in equation (1)] and one with a linear term $\left(a_{1} \neq 0\right)$.

In the other 5 animals conventional pressure/flow studies were done, that is, pressure/flow plots were derived from micturition contractions. The bladder and the distal part of the urethra of these animals were exposed through an abdominal incision. A $24 \mathrm{~g}$ angiocatheter was inserted into the bladder dome. The infusion pump was used to fill the bladder via the catheter with room temperature saline at a rate of $0.53 \mathrm{ml}$. per minute until a micturition contraction occurred.
Pressure was measured via the same catheter with a disposable pressure transducer connected by a Y connector. The pressure loss in the measuring system at the filling rate used was about $0.7 \mathrm{~cm} . \mathrm{H}_{2} \mathrm{O}$. The flow probe was placed around the distal urethra as described earlier and connected to the flowmeter. The pressure and flow rate signals were sampled with a personal computer at a rate of $10 \mathrm{~Hz}$. The filling time was used to calculate the filled volume. The voided volume was collected in a glass funnel and measured. Residual volume was removed from the bladder with a syringe attached to the catheter. The time interval between 2 fillings was 10 to 15 minutes. Test measurements with plastic tubes simulating the urethra showed that the amplitude of the uncalibrated flow rate signal depended on the apposition of tube and flow probe, namely, detachment and reattachment of the flow probe generally resulted in a different amplitude of the flow rate signal at the same imposed flow rate. The variation in the signal amplitude depended on the material and the size of the tube. For this reason, the flow rate signals in all separate micturitions were multiplied by the quotient of the collected voided volume and the integrated flow rate signal as a calibration factor. The pressure and flow rate signals were filtered with a $1 \mathrm{~Hz}$ low pass filter and pressure/flow plots were made (figs. 2 and 3). No lag time correction between the
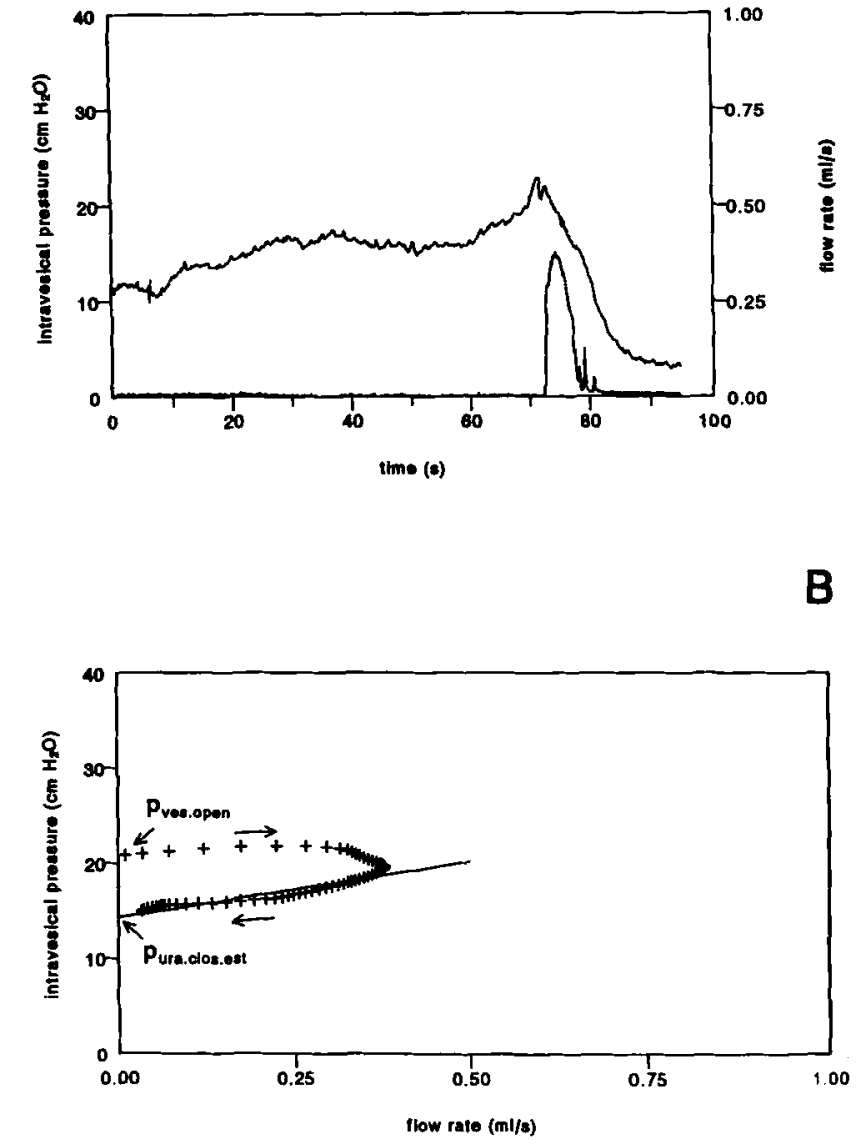

FIG. 2. A, typical example of intravesical pressure and flow rate tracing in pressure/flow study with positive slope of pressure/flow plot. $B$, pressure/flow plot derived from data in $A$. Straight line was fitted to lowest part of plot as selected by algorithm used. $p_{\text {urf }}$ clos.est, estimate for urethral closing pressure, is intercept of this line on

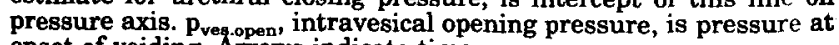
onset of voiding. Arrows indicate time course. 


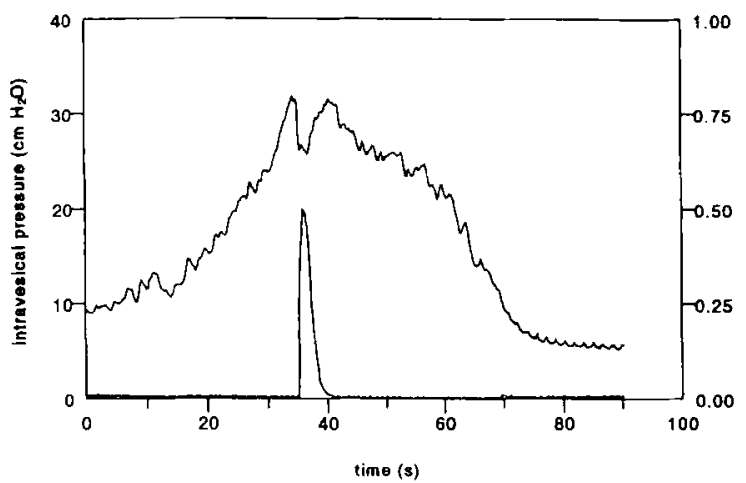

B

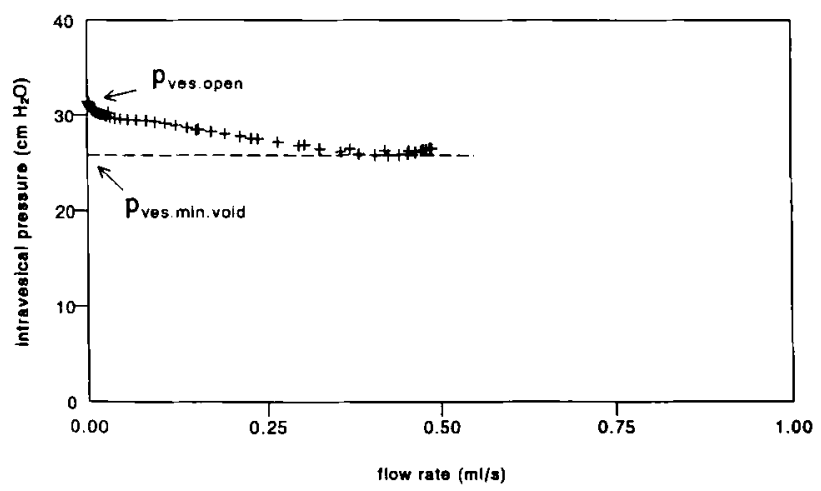

FIG. 3. A, typical example of intravesical pressure and flow rate tracing in pressure/flow study with negative slope of pressure/flow plot. $B$, pressure/flow plot derived from data in $A$. P vesmin.void is minimum pressure attained during voiding.

pressure and flow rate signals was applied as both transducers were situated close together. The lowest part of each pressure/flow plot was selected according to the algorithm described by Kranse and van Mastrigt. ${ }^{4}$ To exclude artifacts in the flow rate signal, only flow rate values exceeding 0.025 $\mathrm{ml}$. per second were used. A straight line was fitted to the selected data. The intercept $p_{\text {ura.closest }}$ on the pressure axis was considered an estimate of the urethral closing pressure. Frequently, the lowest part of the pressure/flow plot was characterized by a negative slope, as in figure $3, \mathrm{~B}$. In those cases the minimum pressure $p_{\text {ves }}$ min void attained during voiding was read from the pressure/flow plot, while no value was assigned to $p_{\text {ura.clos.est. Furthermore, the intravesical }}$ opening pressure $p_{\text {ves open, }}$, defined as the intravesical pressure recorded at the onset of measured flow, 5 was read from the pressure/flow plots (figs. 2 and 3 ). test.

Statistical significance was evaluated with the unpaired $t$

\section{RESULTS}

Figure 1 shows an example of the measured urethral pressure and flow rate at an imposed flow rate of $21.4 \mathrm{ml}$. per minute. The pressure loss that was caused by filling of the bladder and pressure measurement through the same catheter is shown in figure 4. A typical example of the urethral pressure, corrected for the pressure loss, as a function of the

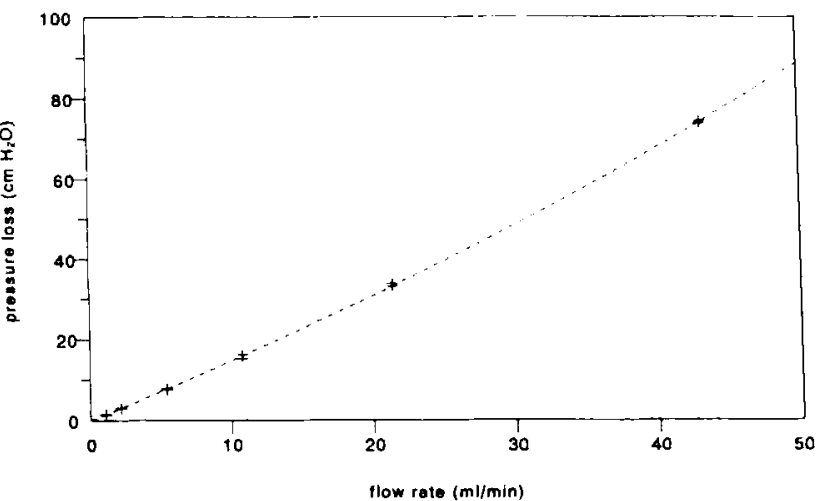

FIG. 4. Pressure loss in measuring system as function of imposed flow rate through it. Dotted line is result of fitting parabolic equation to measured data and is merely meant as guide.

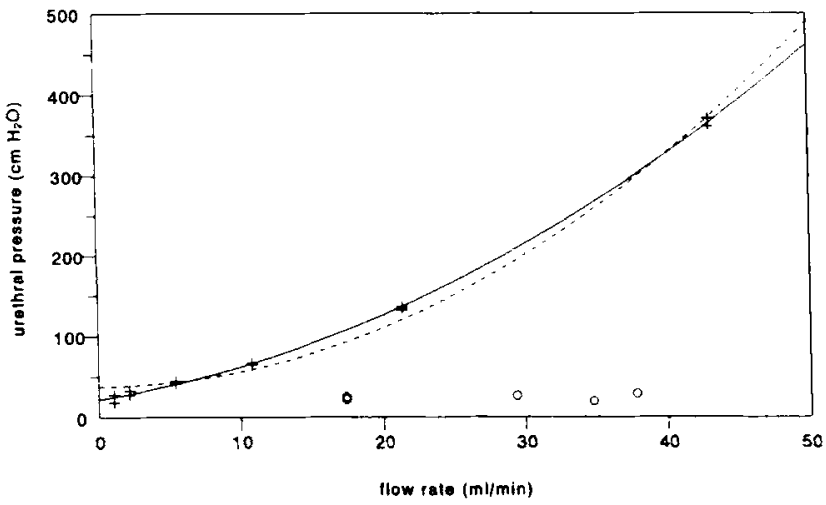

FIG. 5. Urethral pressure as function of imposed flow rate as measured in 1 animal. Crosses indicate measured data values. Solid and dashed curves represent result of fitting a second degree polynomial with and without linear term to data. Circles represent mean $\left(Q_{\max }, p_{\text {ves }}\left(Q_{\text {max }}\right)\right)$ values obtained in 5 animals in which conventional pressure/flow studies were done.

imposed flow rate is shown in figure 5 . A second degree polynomial with and without a linear term fitted to the data is also plotted in the figure. It is obvious that the linear term is necessary to adequately describe the urethral resistance relation. The (corrected) urethral pressure values measured at the imposed flow rates in the 5 animals are summarized in table 1 . The coefficients of equation (1) fitted to this data are shown in table 2 .

In the group of 5 animals in which conventional pressure/ flow studies were done, a total of 31 voidings was analyzed. The mean bladder volume at the onset of micturition was 4.8 \pm 0.3 (standard error of the mean) $\mathrm{ml}$. and the relative residue was $61 \pm 3 \%$. The calibration factor applied to the flow rate signal ranged from 0.009 to 0.049 in all animals as a result of its dependence on the apposition of urethra and flow probe. It varied as much as $40 \%$ within the same animal. The variation between 2 consecutive voidings of the same animal ranged from 0 to $20 \%$ and was $12 \pm 2 \%$ on average. The shape of the pressure/flow plots was not uniform. Typical examples are shown in figures 2,B and 3,B. Analysis was performed as follows: When the intercept of the straight line that was fitted to the lowest part of the pressure/flow plot on the pressure axis exceeded the minimum pressure $p_{\text {ves.min.void, }}$ the latter was recorded. When the intercept did not exceed the minimum pressure, it was considered an estimate for the urethral closing pressure $p_{u r a c l o g}$ and called $p_{\text {uraclosest. Thirteen }}$ pressure/flow plots looked like figure $2, \mathrm{~B}$ and 18 were similar to 
figure 3,B. Both types of plots were found in 4 of the 5 animals. The $p_{\text {ura.clos.est }}$ and $p_{\text {ves.min.void }}$ values and the other parameters derived from the pressure/flow studies are listed in table 3 . The mean $p_{\text {ves.min.void }}$ values in each animal exceeded the mean $p_{u r a . c l o s . e s t}$ values. Because the $p_{\text {ves.min.void values were read }}$ from the pressure/flow plots with a negative slope and the $p_{\text {ura.closest }}$ values were derived from those with a positive slope, this was as expected. The amount of residual urine relative to the bladder volume at the onset of voiding was similar in both types of micturition.

The $p_{\text {uraclos est }}$ values in table 2 , that is, in the unrelaxed urethra, were not significantly different from the purs.cios.est values in table $3(\mathrm{p}=0.91)$. The mean maximum flow rate $\left(Q_{\max }\right)$ values in the pressure/flow studies ranged from 0.29 to $0.63 \mathrm{ml}$. per second, or from 17.4 to $37.8 \mathrm{ml}$. per minute, and occurred at a bladder volume of $4.1 \pm 0.2 \mathrm{ml}$. on average. The pressure values $p_{\text {ves }}\left(Q_{\max }\right)$ at these flow rates ranged from 19.4 to $28.8 \mathrm{~cm} . \mathrm{H}_{2} \mathrm{O}$. It can be seen from figure 5 that these pressures are much lower than the pressures measured in the unrelaxed urethra in the same flow rate range. The pressure at which voiding started exceeded the urethral closing pressure by $9 \mathrm{~cm} \cdot \mathrm{H}_{2} \mathrm{O}$ on average.

\section{DISCUSSION}

Micturition is initiated by relaxation of the external urethral sphincter. ${ }^{6}$ The decrease in resistance of the urethra to urinary flow is caused by a change in neurogenic stimulation. It was the aim of this study to investigate this mechanism. The resistance to flow of the unrelaxed urethra in the guinea pig was measured by forcing saline through the urethra with an infusion pump. The results were compared with pressure/ flow plots of voidings in these animals, where the urethra was (more) relaxed. Theoretically, in the former type of measurements (some) urethral relaxation may have been caused as a result of Barrington's (doubtful) fourth micturition reflex, which states that urethral flow induces sphincter relaxation. ${ }^{7}$ Relaxation in the "unrelaxed urethra" could therefore not be excluded beforehand. Moreover, it could not be excluded that urethral tone was influenced by the anesthetic used. Consequently, it cannot be stated that, in the 2 types of measurement, the urethra was fully contracted and fully relaxed. However, the pressures measured in both conditions were very different indeed, so that it is obvious that the measurements were performed at 2 very different levels of urethral relaxation. The dependence of the urethral resistance relation on the stimulation intensity could therefore be studied.

In the unrelaxed urethra the urethral resistance relation could adequately be described by a second degree polynomial with a non-zero linear term. It would have been most logical to fit second degree polynomials to the pressure/flow data in the relaxed urethra as well. However, this was not useful as a result of the variation in shape of the plots. Studies in humans also indicated that pressure/flow plots show a wide variety of shapes such that many different classes of mathematical functions have been proposed to describe them. ${ }^{8-10}$ In most cases a straight line suffices to quantify the degree of urethral resistance during voiding. ${ }^{11}$ Moreover, most often a simple straight line is the most complicated mathematical function that can reliably be fitted to pressure/flow data. As a result of the considerable variability of such data the parameters of more complicated functions cannot reliably be determined. ${ }^{12}$ The variety of shapes in pressure/flow plots can be explained by the fact that the course of micturition not only depends on urethral properties, but also on properties of the detrusor muscle and the intensity of neurogenic stimulation. Notwithstanding the differences in measurement accuracy, the urethral resistance relation in the contracted and relaxed urethra could adequately be compared in the present study. It was found that the intercept of the pressure axis was the same in both conditions, but the steepness of the curve was largely different. It can thus be concluded that the urethral resistance relation rotates around the urethral closing pressure and simultaneously flattens when the urethral musculature relaxes, as illustrated in figure 6 . The independence of the urethral closing pressure of the state of relaxation seems in correspondence with Schäfer's qualitative description of the urethral resistance relation in case of a urethral stricture. ${ }^{8}$ In this author's view such a stricture steepens the urethral resistance relation but leaves the intercept on the pressure axis unaltered. On the other hand, the low value that we found for the urethral closing pressure in the contracted state seems to contradict the results of static urethral pressure profile measurements in humans. Typically, maximum pressures of about $100 \mathrm{~cm} . \mathrm{H}_{2} \mathrm{O}$ are measured in such studies. ${ }^{13}$ It should be recognized, however, that these pressure values may overestimate the real urethral pressure because of the size of the measuring catheter. ${ }^{14}$ Assuming that our results can be extrapolated to the human situation, it follows that the effect of the catheter on the measured pressure is very large indeed, as is suggested by Griffiths' illustration 5.6. ${ }^{14}$

According to the simple view that, upon relaxation, the urethral resistance relation rotates around the intercept on the pressure axis, it is to be expected that voiding starts when the intravesical pressure equals the urethral closing pressure. In our measurements this was not the case. Voiding started only when the intravesical pressure reached a systematically higher pressure value (table 3 ). The same is usually observed in humans. ${ }^{15}$ Videoscopic studies in humans show that voiding is preceded by funnelling of the bladder neck, which is believed to be initiated by pelvic floor and urethral sphincter relaxation. ${ }^{16,17}$ This renders it unlikely that the high intravesical pressure recorded at the onset of voiding, after the funnelling of the bladder neck, can be ascribed to this part of the tract. This view is supported by the general assumption that the bladder neck plays only a passive role in maintaining continence. ${ }^{17}$ In a study on the pig ureter, Griffiths and Notschaele noted that the pressure needed to open the collapsed ureter was a few $\mathrm{cm} . \mathrm{H}_{2} \mathrm{O}$ higher than the pressure needed to keep the ureter open. ${ }^{18}$ As the walls of the collapsed ureter thus seem to stick together, the difference in the two pressures was called the unsticking pressure. The difference between the intravesical opening pressure and the urethral closing pressure might represent a similar unsticking pressure of the urethra. This explanation

TABLE 1. Values of the urethral pressure measured at imposed flow rates in the unrelaxed urethras of 5 guinea pigs

\begin{tabular}{|c|c|c|c|c|c|c|}
\hline $\begin{array}{l}\text { Flow rate } \\
\text { guinea pig }\end{array}$ & $1.1 \mathrm{ml} / \mathrm{min}$ & $2.2 \mathrm{ml} . / \mathrm{min}$ & $5.4 \mathrm{ml} / \mathrm{min}$ & $10.8 \mathrm{ml} . / \mathrm{min}$ & $21.4 \mathrm{ml} / \mathrm{min}$ & $43.0 \mathrm{ml} / \mathrm{min}$ \\
\hline 1 & $23 \pm 5$ & $30 \pm 3$ & $43 \pm 0.4$ & $66 \pm 1$ & $135 \pm 2$ & $366 \pm 5$ \\
\hline 2 & $24 \pm 3$ & $31 \pm 9$ & $47 \pm 2$ & $91 \pm 15$ & $153 \pm 3$ & $406 \pm 6$ \\
\hline 3 & $25 \pm 1$ & $31 \pm 2$ & $42 \pm 1$ & $71 \pm 5$ & $161 \pm 12$ & $351 \pm 6$ \\
\hline 4 & $28 \pm 3$ & $31 \pm 4$ & $48 \pm 2$ & $81 \pm 3$ & $155 \pm 0.3$ & $377 \pm 6$ \\
\hline 5 & $17 \pm 1$ & $23 \pm 1$ & $42 \pm 2$ & $88 \pm 3$ & $196 \pm 10$ & $527 \pm 19$ \\
\hline mean & $23 \pm 2$ & $29 \pm 1$ & $45 \div 1$ & $79 \pm 4$ & $160 \pm 9$ & $406 \pm 28$ \\
\hline
\end{tabular}

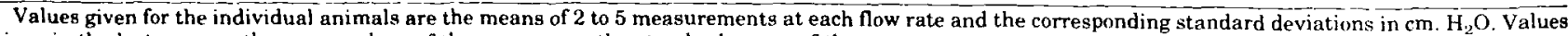
given in the last row are the mean values of these means \pm the standard errors of the mean. 
TABLE 2. Values of the parameters $p_{\text {uractresent, }} a_{1}$ and $a_{2}$ obtained from fitting equation (1) to the pressure / flow data measured in the unrelaxed urethra of 5 guinea pigs

\begin{tabular}{|c|c|c|c|}
\hline Guinea pig & puratcosust $\left(\mathrm{cm} \cdot \mathrm{H}_{2} \mathrm{O}\right)$ & $\left.\mathrm{a}_{1}\left(\mathrm{~cm} \cdot \mathrm{H}_{2} \mathrm{O} / \mathrm{m}\right] / \mathrm{min}.\right)$ & $\mathrm{a}_{2}\left(\mathrm{~cm} . \mathrm{H}_{2} \mathrm{O} /(\mathrm{ml} / \mathrm{min})^{2^{2}}\right)$ \\
\hline 1 & $22.7 \pm 2.0$ & $2.64 \pm 0.28$ & $0.124 \pm 0.006$ \\
\hline 2 & $22.2 \pm 5.5$ & $4.30 \div 0.84$ & $0.107+0.019$ \\
\hline 3 & $15.8 \pm 4.9$ & $5.39 \pm 0.63$ & $0.057 \pm 0.014$ \\
\hline 4 & $22.1 \pm 2.1$ & $4.32 \pm 0.32$ & $0.091 \pm 0.007$ \\
\hline 5 & $10.2 \pm 4.7$ & $5.44 \pm 0.68$ & $0.153 \pm 0.015$ \\
\hline mean & $18.6 \pm 2.2$ & $4.42 \pm 0.46$ & $0.106=0.014$ \\
\hline
\end{tabular}

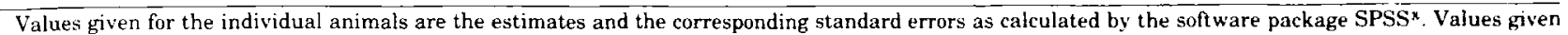
in the last row are the mean values of these estimates \pm the standard errors of the mean.

TABLE 3. Values of the parameters studied in the conventional pressure/flow studies in 5 guinea pigs

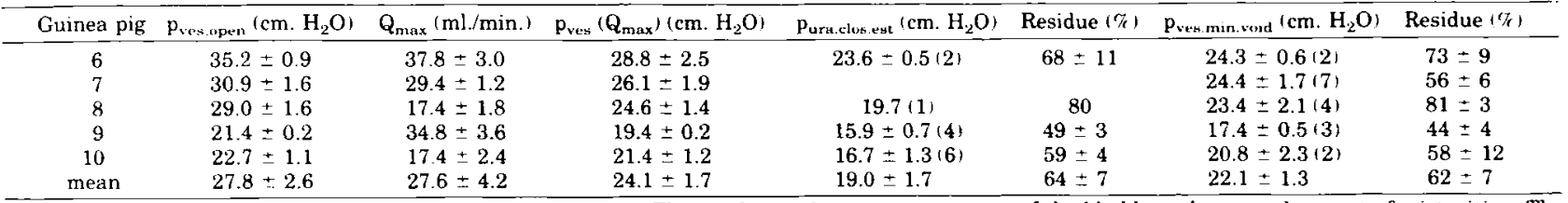

Values given are mean values \pm standard errors of the mean. The residue is given as a percentage of the bladder volume at the onset of micturition. The

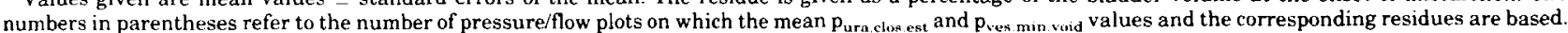
The mean values of the other parameters are based on all pressure/flow studies in each animal.

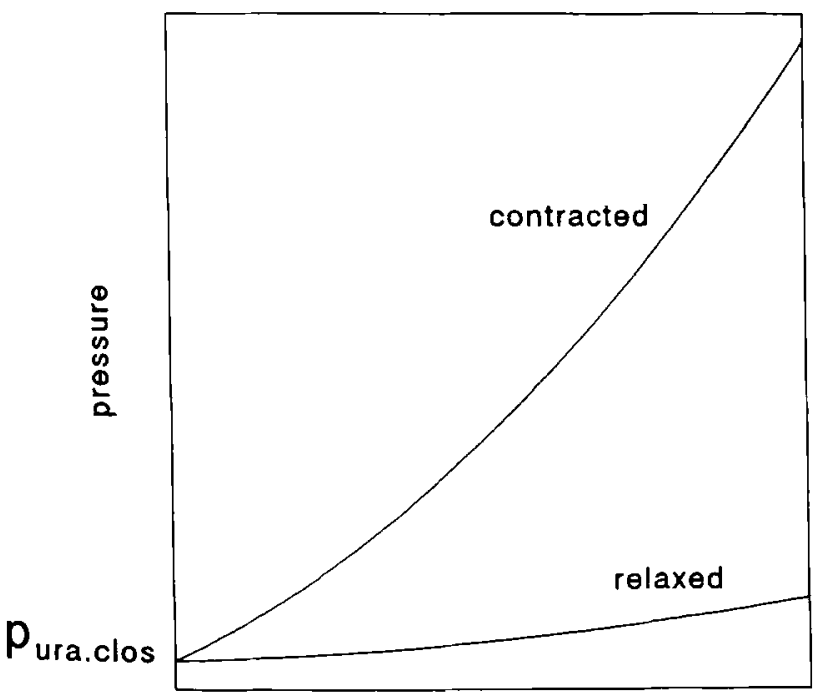

flow rate

FIG. 6. Schematic representation of dependence of urethral resistance relation on degree of relaxation of urethral musculature.

would be in line with experiments of Zinner et al., who showed that a higher pressure head was needed to cause leakage in a collapsible tube when the inner surface was coated with grease. ${ }^{19}$ An alternative explanation is that the pressure difference must be ascribed to the viscoelastic properties of the urethra. Thind et al. studied the pressure response after inflation of a balloon located in the urethra. ${ }^{20}$ It was found that, upon balloon inflation, the urethral pressure rose to a value higher than the eventual equilibrium value. The dynamic pressure excess increased with an increasing rate of balloon inflation.

A large amount of residual urine is frequently found in anesthetized animals, as in this study. ${ }^{21}$ Analysis of pressure/flow plots might contribute to understanding the cause of this. After the micturition corresponding to figure 2 the residue was $58 \%$ and seemed to be caused by a premature fading of the bladder contraction. After the micturition of figure 3 the residue was $64 \%$. In this case bladder contraction was sustained for about 30 seconds, but premature closing of the urethral sphincter, signified by a rise of pressure to its isovolumetric value, prevented further bladder emptying. It could be hypothesized that the course of micturition, as in figure 2 or figure 3 , depends on the depth of anesthesia. In our measurements no relation between the course of micturition and the duration of the experiment was found. It thus seems that the efficiency of voiding in urethane-anesthetized guinea pigs may be reduced both by insufficiently sustained bladder contraction and by dyssynergic voiding.

\section{REFERENCES}

1. Groen, J., van Mastrigt, R. and Bosch, R.: Contractility of the guinea pig bladder measured in situ and in vitro. Neurourol. Urodyn., 13: 587, 1994.

2. Groen, J., van Mastrigt, R. and Bosch, R.: Neurogenic modula tion of micturition: the relation between stimulation intensity and the maximum shortening velocity of the guinea pig detrusor muscle. J. Urol., 153: 228, 1995.

3. Griffiths, D. J.: The mechanics of the urethra and of micturition. Br. J. Urol., 45: 497, 1973

4. Kranse, $M$. and van Mastrigt, $R$.: A computer algorithm to detect the lowest monotonically increasing part of a pressure flow plot. Neurourol. Urodyn., 10: 293, 1991.

5. International Continence Society: Standardisation of terminology of lower urinary tract function: pressure-flow studies of voiding, urethral resistance and urethral obstruction. Draft, 1995.

6. Tanagho, E. A.: The anatomy and physiology of micturition. Clin. Obstet. Gynaecol., 5: 3, 1978.

7. Morrison, J. F. B.: Reflex control of the lower urinary tract. In: The Physiology of the Lower Urinary Tract. Edited by M. Torrens and J. F. B. Morrison. London: Springer-Verlag, chapt. 7, pp. 207-208, 1987.

8. Schäfer, $W$.: The contribution of the bladder outlet to the relation between pressure and flow rate during micturition. In: Benign Prostatic Hypertrophy. Edited by F. Hinman, Jr. New YorkHeidelberg-Berlin: Springer-Verlag, pp. 470-498, 1983.

9. Griffiths, D., van Mastrigt, R. and Bosch, R.: Quantification of urethral resistance and bladder function during voiding, with special reference to the effects of prostate size reduction on urethral obstruction due to benign prostatic hyperplasia. Neurourol. Urodyn., 8: 17, 1989.

10. Spángberg, A., Terio, H., Engberg, A. and Ask, P.: Quantification of urethral function based on Griffiths' model of flow through elastic tubes. Neurourol. Urodyn., 8: 29, 1989.

11. Schäfer, W.: Basic principles and clinical application of advanced analysis of bladder voiding function. Urol. Clin. North Am., 17: 553,1990 . 
12. Kranse, $M$. and van Mastrigt, R.: Fitting orthogonal polynomials to the lowest part of a pressure flow plot. Neurourol. Urodyn., 10: $290,1991$.

13. Torrens, M.: Urodynamics. In: The Physiology of the Lower Urinary Tract. Edited by M. Torrens and J. F. B. Morrison. London: Springer-Verlag, chapt. 9, pp. 297-301, 1987.

14. Griffiths, D. J.: Hydrodynamics and mechanics of the bladder and urethra. In: Urodynamics: Principles, Practice and Application, 2nd edition. Edited by A. R. Mundy, T. P. Stephenson and A. J. Wein. New York: Churchill Livingstone, chapt. 5, pp. 75-77, 1994.

15. Griffiths, D. J.: Urodynamics (Medical Physics Handbooks 4). Bristol: Adam Hilger Ltd., pp. 130-132, 1980.

16. Tanagho, E. A. and Miller, E. R.: Initiation of voiding. Br. J. Urol., 42: 175, 1970 .

17. Torrens, M.: Human physiology. In: The Physiology of the Lower
Urinary Tract. Edited by M. Torrens and J. F. B. Morrison. London: Springer-Verlag, chapt. 11, pp. 343-344, 1987.

18. Griffiths, D. J. and Notschaele, C.: The mechanics of urine transport in the upper urinary tract: $I$. The dynamics of the isolated bolus. Neurourol. Urodyn., 2: 155, 1983.

19. Zinner, N. R., Sterling, A. M. and Ritter, R. C.: Role of inner urethral softness in urinary continence. Urology, 16: 115, 1980.

20. Thind, P., Lose, G. and Colstrup, H.: Resistance to forced opening of the resting urethra in healthy females assessed by experimental simulation of urine ingression. Neurourol. Urodyn., 11: 201, 1992.

21. van Asselt, E., Groen, J. and van Mastrigt, R.: A comparative study of voiding in the rat and the guinea pig: simultaneous measurement of flow rate and pressure. Am. J. Physiol., 269: $\mathrm{R} 98,1995$. 